ISSN 0103-9954

\title{
MINIESTAQUIA EM SISTEMA DE HIDROPONIA E EM TUBETES DE CORTICEIRA-DO-MATO
}

\section{MINICUTTING IN HYDROPONICS SYSTEM AND IN PLASTIC TUBES CORTICEIRA-DO-MATO}

\author{
Ana Catarina M. C. Mori da Cunha ${ }^{1} \quad$ Ivar Wendling $^{2} \quad$ Levi Souza Júnior $^{3}$
}

RESUMO

Este trabalho objetivou avaliar a técnica de miniestaquia como método de propagação vegetativa de corticeira-do-mato (Erythrina falcata Benth.) quanto à produção e sobrevivência das minicepas nas sucessivas coletas, quanto ao percentual de enraizamento e do crescimento em altura e ainda o diâmetro do coleto das mudas originadas, comparando dois sistemas de manejo na formação do minijardim clonal (sistema hidropônico e em tubetes). As minicepas foram obtidas partindo de mudas produzidas via sementes de corticeira-do-mato, das quais se promoveram podas e coletas sucessivas de miniestacas. Os resultados demonstraram a eficiência da técnica para a propagação vegetativa dessa espécie, atingindo média geral de 85,5\% de enraizamento. Em termos gerais, a miniestaquia de corticeira-do-mato, partindo de material de origem seminal, é uma popção para produção de mudas dessa espécie, nas condições em que a semente é um insumo limitante ou com problemas de germinação. Nas condições em que foram conduzidos os estudos podem ser obtidas mudas aptas para o plantio definitivo entre quatro a cinco meses de idade.

Palavras-chave: propagação de plantas; Erythrina falcata; enraizamento; miniestaquia.

\section{ABSTRACT}

This work aimed to evaluate the minicutting technique as a method for vegetative propagation of corticeira-do-mato (Erythrina falcate Benth.) in terms of the production, survival of the ministumps after successive collections of minicuttings, as well as rooting and growth (height and root collar diameter) of the formed seedlings, being compared two handled systems (in hydroponics systems and in plastic tubetes). The ministumps were obtained from seedlings of Erythrina falcata, where successive collections of minicuttings were promoted. Results demonstrated to the efficiency of the technique for the vegetative propagation of this species, reaching average generality of $85,5 \%$ of rooting. In general terms, the minicuttings technique, from seminal material, is an alternative for production of seedlings of this species during the whole year and in the conditions that the seeds are limiting input or with germination problems. In the same conditions that the studies were led obtained seedlings can be gotten for the definitive planting between four to five months of age.

Keywords: plant propagation; Erythrina falcata; rooting; minicutting.

\section{INTRODUÇÃO}

A corticeira-do-mato (Erythrina falcata Benth.) é uma espécie nativa do Brasil, ocorrendo nos estados de Minas Gerais e Mato Grosso do Sul até o Rio Grande do Sul (LORENZI, 1992), sendo também encontrada de forma natural na Argentina, na Bolívia, no Paraguai e no Peru. O interesse pelo seu cultivo está relacionado ao seu potencial paisagístico (por apresentar flores atraentes e vistosas, com excelente efeito decorativo) e para recuperação de ecossistemas degradados e restauração de mata ciliar em locais com inundação periódica e de rápida duração, sendo também indicada para plantio em áreas com solo permanentemente encharcado, além da manutenção da fauna silvestre (CARVALHO, 2003).

Russo et al. (1993) citam inúmeros usos para o gênero Erythrina, sendo os principais: medicinal; madeira; artesanato; alimentação; ornamental; fibras; corantes e desenvolvimento de sistemas agroflorestais. O rápido crescimento das plantas, o potencial fixador de nitrogênio e a alta produção de biomassa tornam o gênero muito atrativo, sendo esse último o produto mais importante das árvores do gênero porque protege o solo contra erosão e a danos contra extremos de temperatura, vento e chuvas. Sem ser podada produz cerca

1. Engenheira Florestal, Doutoranda pelo Programa de Pós-Graduação em Ciência Florestal, Universidade Federal de Viçosa, Campus Universitário, CEP 36570-000, Viçosa (MG). catarina_mori@yahoo.com.br

2. Engenheiro Florestal, Dr., Pesquisador do Centro Nacional de Pesquisas de Florestas, EMBRAPA, Estrada da Ribeira, Km 111, Caixa Postal 319, CEP 83411-000, Colombo (PR). ivar@cnpf.embrapa.br

3. Biólogo, M.Sc., Universidade Federal do Paraná, Caixa Postal 19031, CEP 81531-990, Curitiba (PR). ljrsouza@yahoo.com.br

Recebido para publicação em 21/09/2004 e aceito em 12/11/2007. 
de 0,8 a 5 t/ha/ano de peso seco de manta orgânica e quando podadas, podem alcançar até $10 \mathrm{t} / \mathrm{ha} / \mathrm{ano}$, incluindo folhas e galhos (RUSSO, 1984).

A multiplicação da corticeira por sementes encontra algumas dificuldades, pois somente $6 \%$ das flores desenvolvem sementes em populações naturais bem conservadas, além da autogamia (que tende a ocorrer em sítios de coleta brasileiros, por causa da fragmentação da floresta original) que prejudica toda a produção de sementes. Há ainda um forte ataque de besouros aos frutos e as sementes têm germinação irregular no tempo (NEIL apud CARPANEZZI, 2001).

Nos últimos 20 anos, as técnicas usadas nos minijardins clonais tiveram uma evolução muito grande na forma, com redução da área, incremento na produtividade e diminuição do tamanho das estacas (HIGASHI et al., 2002). O jardim clonal pode ser instalado em diversos tipos de recipientes, que variam desde vasos de polipropileno de diferentes volumes, caixas de fibras de vidro de variadas formas e dimensões ou em canaletões de fibro-cimento (HIGASHI et al., 2000; SILVEIRA, 2001; HIGASHI et al., 2002), atualmente o mais utilizado em empresas florestais que trabalham com espécies do gênero Eucalyptus (HIGASHI et al., 2002), sendo que os substratos mais utilizados para esse sistema são a areia e o cascalho, por apresentarem características físicas e químicas adequadas para esta finalidade, sendo o mais utilizado a areia lavada.

O rápido desenvolvimento das essências exóticas e a necessidade de sua reprodução imediata, fizeram com que diversos trabalhos fossem realizados no sentido de se estudar as técnicas de propagação vegetativa. No entanto, informações existentes sobre o comportamento de essências florestais nativas são escassas em face de metodologia usada para as essências exóticas (SILVA, 1982).

Nos sistemas de hidroponia os nutrientes são fornecidos à planta por gotejamento, regulando-se a concentração e a vazão de nutrientes de modo que se tenha um excedente muito pequeno, que é recolhido por um sistema de drenagem ao fundo do canaletão ou sob o solo e então descartado (HIGASHI et al., 2002).

Para Santos et al. (2000a), a aplicabilidade da miniestaquia em espécies nativas é uma opção para a propagação vegetativa de algumas espécies que têm as sementes com baixo potencial de germinação, dificuldade de armazenamento e/ou são insumo limitantes. Estudos realizados revelaram que esta técnica é viável para o enraizamento de miniestacas coletadas de minicepas produzidas partindo de sementes em espécies nativas como o jequitibá rosa, cedro rosa, mogno e sete cascas (SANTOS et al., 2000b; SANTOS et al., 2001; XAVIER et al., 2002).

Com base no exposto, o objetivo deste trabalho foi avaliar a eficiência da técnica de miniestaquia e comparar os sistemas empregados no manejo das minicepas (hidropônico e tubetes) na propagação vegetativa de corticeira-do-mato quanto à produção e sobrevivência das minicepas nas sucessivas coletas e no enraizamento, crescimento em altura e diâmetro do colo das mudas produzidas via miniestaquia.

\section{MATERIAL E MÉTODOS}

O experimento foi conduzido na Embrapa Florestas, em Colombo, PR. As plantas de corticeira-do-mato foram produzidas com base em sementes, as quais foram coletadas de quatro árvores matrizes nos municípios de Curitiba e Colombo, PR.

As plantas com aproximadamente de $15 \mathrm{~cm}$ de altura, aos sete meses de idade, foram decepadas a uma altura de $10 \mathrm{~cm}$ da base, para estimular as brotações nas minicepas, formando o minijardim clonal, conforme procedimentos da técnica descrita por Xavier e Wendling (1998) e Wendling (1999).

O experimento foi conduzido no período de setembro de 2003 a fevereiro de 2004. O minijardim clonal localizou-se em condições de estufa, constituído por 120 minicepas, dispostas em delineamento inteiramente casualisado, com quatro repetições de 15 minicepas por repetição, sendo metade manejada em sistema hidropônico (canaletão de areia) e a outra metade em tubetes de $110 \mathrm{~cm}^{3}$. No primeiro sistema, foram fornecidos diariamente nutrientes por gotejamento $\left(5 \mathrm{~L} \mathrm{~m}^{-2}\right)$, sendo a solução nutritiva composta por: monoamônio fosfato $\left(40 \mathrm{mg} \mathrm{L}^{-1}\right)$; nitrato de potássio hidro $\left(440 \mathrm{mg} \mathrm{L}^{-1}\right)$; sulfato de amônio $\left(310 \mathrm{mg} \mathrm{L}^{-1}\right)$; cloreto de cálcio (790 $\left.\mathrm{mg} \mathrm{L}^{-1}\right)$; uréia $\left(10 \mathrm{mg} \mathrm{L}^{-1}\right)$; sulfato de magnésio $\left(400 \mathrm{mg} \mathrm{L}^{-1}\right)$; ácido bórico $\left(2,88 \mathrm{mg} \mathrm{L}^{-}\right.$ $\left.{ }^{1}\right)$; sulfato de manganês $\left(3,7 \mathrm{mg} \mathrm{L}^{-1}\right)$; molibdato de sódio $\left(0,18 \mathrm{mg} \mathrm{L}^{-1}\right)$; sulfato de zinco $\left(0,74 \mathrm{mg} \mathrm{L}^{-1}\right)$ e hidroferro em pó $\left(81,8 \mathrm{mg} \mathrm{L}^{-1}\right)$. Para o segundo sistema, a adubação foi realizada semanalmente, com 
solução nutritiva de mesma composição, sendo colocado $6 \mathrm{~mL}$ dessa solução em cada tubete.

Em intervalos regulares de 15 dias, foram coletadas miniestacas das minicepas conduzidas em sistema hidropônico, onde foram realizadas oito coletas. Já para o sistema de manejo em tubetes o intervalo foi de 30 dias, sendo realizadas quatro coletas, sendo que as coletas pares foram realizadas aos mesmo tempo em ambos os sistemas empregados. As miniestacas coletadas foram confeccionadas com tamanho entre 3 e 5 $\mathrm{cm}$, com um par de folhas recortadas em 1/3 de sua área original. Imediatamente após a coleta as miniestacas foram acondicionadas em caixa de isopor contendo água. Para o enraizamento, não foram aplicados reguladores de crescimento nas miniestacas, e estas foram colocadas em casa de vegetação com temperatura entre 25 e $30^{\circ} \mathrm{C}$ e umidade controlada (> 80\%). Os recipientes utilizados foram tubetes de $55 \mathrm{~cm}^{3}$, e o substrato constituído de casca de arroz carbonizada (35\%), vermiculita de granulometria fina (35\%) e substrato orgânico (30\%). Não foi realizado nenhum tratamento de desinfestação previamente a introdução das miniestacas no substrato. Na Figura 1, é apresentado o esquema de miniestaquia utilizado no presente estudo para corticeira-do-mato. O período de permanência em casa de vegetação para indução de enraizamento foi de 30 dias, sendo em seguida as miniestacas transferidas para casa de sombra por um período de 20 dias e, posteriormente para uma área de pleno sol por mais 20 dias.

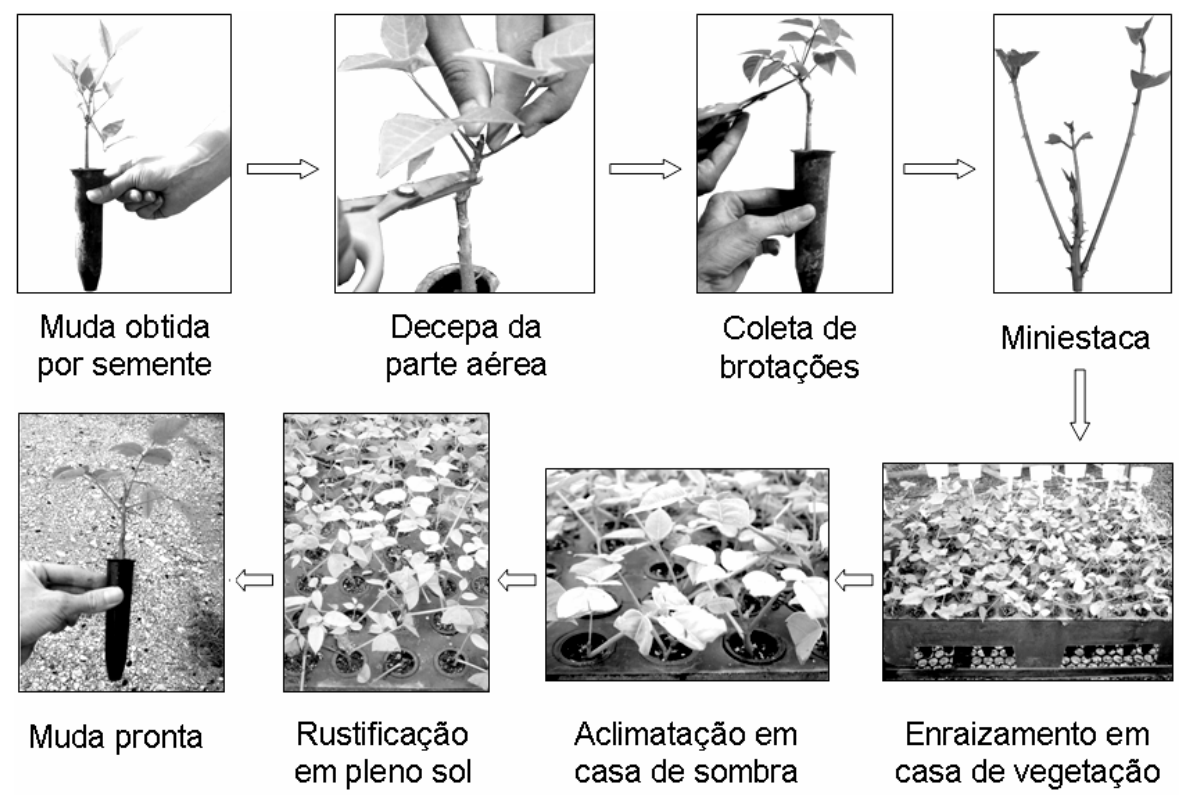

FIGURA 1: Esquema do processo de miniestaquia de corticeira-do-mato (Erythrina falcata).

FIGURE 1: Illustrative model of minicuttings technique used for vegetative propagation of corticeira-domato (Erythrina falcata).

Partindo da transferência para casa de sombra até o final da fase de pleno sol as plantas foram adubadas semanalmente com $6 \mathrm{~mL}$ por planta, da seguinte formulação: sulfato de amônio $\left(4,0 \mathrm{~g} \mathrm{~L}^{-1}\right)$, superfosfato simples $\left(10,0 \mathrm{~g} \mathrm{~L}^{-1}\right)$, cloreto de potássio $\left(4,0 \mathrm{~g} \mathrm{~L}^{-1}\right)$ e solução de micronutrientes $\left(1,0 \mathrm{~g} \mathrm{~L}^{-1}\right.$, composta por: $9 \%$ de $\mathrm{Zn} ; 1,8 \%$ de $\mathrm{Br} ; 0,8 \%$ de $\mathrm{Cu} ; 3 \%$ de Fe; $2 \%$ de Mn e 0,12\% de Mo). A irrigação e os tratos silviculturais foram os necessários à obtenção do crescimento vigoroso das mudas.

As avaliações realizadas constituíram-se de sobrevivência e produtividade das minicepas no decorrer das oito coletas para o sistema hidropônico e quatro coletas para o sistema em tubetes e, em relação as miniestacas: sobrevivência na saída da casa de vegetação (\% de enraizamento), sobrevivência na saída da casa de sombra, sobrevivência a pleno sol, altura e diâmetro do coleto das mudas.

O delineamento experimental utilizado foi o inteiramente casualizado, com quatro repetições e 15 miniestacas por parcela. Os resultados foram submetidos à análise de variância e os dados foram discriminados pelo teste de Tukey, a 5\% de probabilidade. 


\section{RESULTADOS E DISCUSSÃO}

As oito coletas sucessivas de miniestacas não afetaram significativamente a sobrevivência das minicepas em nenhum dos sistemas estudados, uma vez que a média para a sobrevivência em sistema de hidroponia foi de $98,7 \%$ e para os tubetes não houve mortalidade (100\% de sobrevivência), durante o período do experimento. Essa elevada sobrevivência revela uma adequabilidade dos tratos culturais empregados, como ótimos níveis nutricionais, hídricos e manejo das minicepas, o que indica a possibilidade de utilização desses sistemas de minijardim clonal para a produção de brotações (miniestacas) para essa espécie. Conforme pode ser observado na Figura 2, obteve-se uma produtividade média de 2,9 miniestacas por minicepa por coleta para o canaletão e para o tubete 1,3 (para as quatro coletas realizadas neste sistema), o que indica a habilidade e a capacidade de produção de novas brotações das minicepas após cada coleta de miniestacas. A menor produtividade observada na primeira coleta, nos dois sistemas empregados, foi decorrente do fato de a minicepa ainda não se encontrar com sua formação ideal (maior número de gemas com possibilidade de produzir miniestacas).

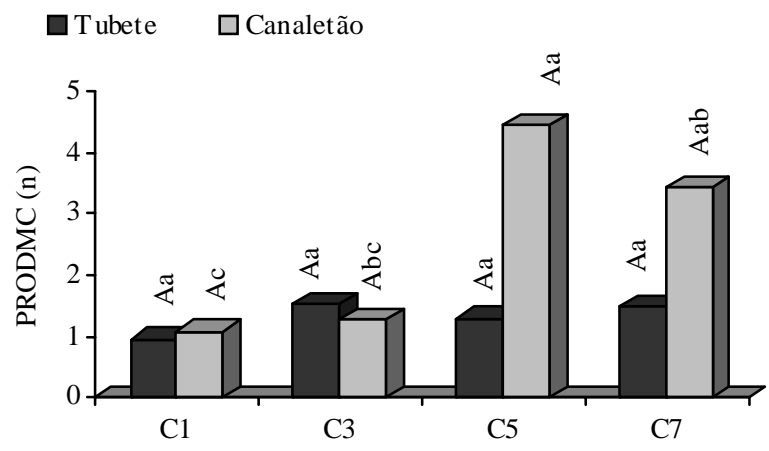

FIGURA 2: Número de miniestacas por minicepa (PRODMC), em função do número de coletas efetuadas no minijardim clonal de Erythrina falcata, para o sistema de cultivo hidropônico e tubete. As médias seguidas de uma mesma letra maiúscula entre os tratamentos na mesma coleta e letras minúsculas entre coletas, dentro de um mesmo tratamento, não diferem entre si pelo teste de Tukey a 5\% de probabilidade.

FIGURE 2: Number of ministumps per minicuttings in relation to the number of collections carried out in the clonal minigardem of Erythrina falcata, to the hydroponic system and in plastic tubes. Means followed by the same capital letter among the treatments in the same collection and lower case among the collections, inside the same treatment, don't have differences by Tukey's Test $(\mathrm{p}<0,05)$.

Entre os tratamentos nas sucessivas coletas foram analisadas somente as coletas ímpares, nas quais foram coletadas miniestacas nos dois sistemas empregados, e verificou-se que não há diferença entre os sistemas de manejo adotado (Figura 2). Entretanto, o número de miniestacas produzidas pelo sistema hidropônico é consideravelmente superior, visto que as coletas são realizadas com uma maior freqüência. Já entre as coletas, para tubetes não foi constatada diferença significativa e para o canaletão os resultados superiores foram observados partindo da coleta 5, com ligeira queda partindo da coleta 7. Esse comportamento pode ser resultado de uma adaptação das minicepas à quebra de dominância apical após a primeira poda e a reorganização do sistema de crescimento ortotrópico para um sistema plagiotrópico. Deste modo, após a primeira coleta, as gemas dormentes tornaram-se ativas, resultando em maior estímulo ao crescimento (WENDLING e SOUZA JÚNIOR, 2003).Os resultados também indicam a não-exaustão das minicepas com o decorrer das coletas.

Para Eucalyptus, a produção de miniestacas por minicepa é variável conforme o sistema de jardim miniclonal adotado, sendo as médias de produção encontradas em literatura as seguintes: 5,6 miniestacas por minicepa em cada coleta em sistema de hidroponia em canaletão a cada 5-10 dias (WENDLING, 2002); 1,9 miniestacas no sistema de minijardim clonal em tubete a cada 20 dias (WENDLING, 1999); 2,4 miniestacas por minicepa no sistema de tubetes com fertirrigação por inundação a cada 7 dias (TITON, 2001). 
Para espécies nativas, Santos (2002 a) utilizou sistemas de jardim miniclonal em tubetes de $200 \mathrm{~cm}^{3}$, com coletas a cada 30 dias obtendo as seguintes produções de miniestacas por minicepa: 1,3 para cedro rosa; 1,1 para mogno; 1,6 para angico vermelho e 3,8 para jequitibá rosa. Já Wendling e Souza Júnior (2003), trabalhando com erva-mate verificaram uma produção de 2,2 miniestacas por minicepa, em intervalo de 35 dias entre as coletas.

Com relação ao sistema em tubetes, essas referências denotam que o presente estudo tem resultados compatíveis com outras espécies, sobretudo para nativas. Já para o canaletão, os resultados de literatura demonstram que para Eucalyptus essas médias foram superiores.

Quanto ao enraizamento das miniestacas, foram avaliadas as coletas 1,3 e 5, as quais não foram submetidas a nenhum tratamento hormonal. Nas avaliações de sobrevivência na saída da casa de vegetação, saída da casa de sombra e na sobrevivência a pleno sol não foram observadas diferenças significativas entre os tratamentos, nas três coletas (Figura 3). Para o sistema de tubetes, não foi verificada diferença significativa em nenhuma das características, entretanto para o sistema hidropônico a coleta 5 mostrou-se superior em todas as variáveis.

A

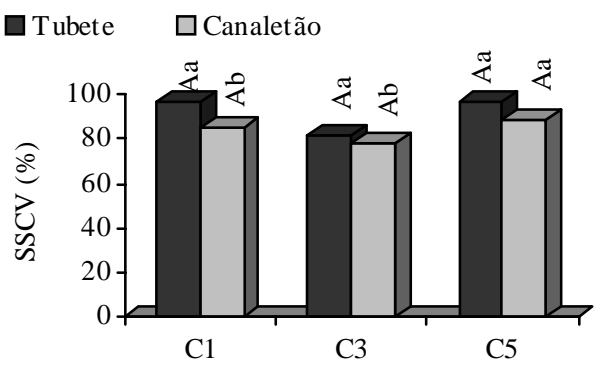

B

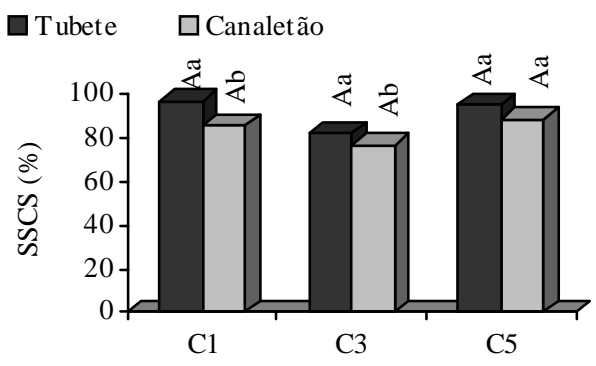

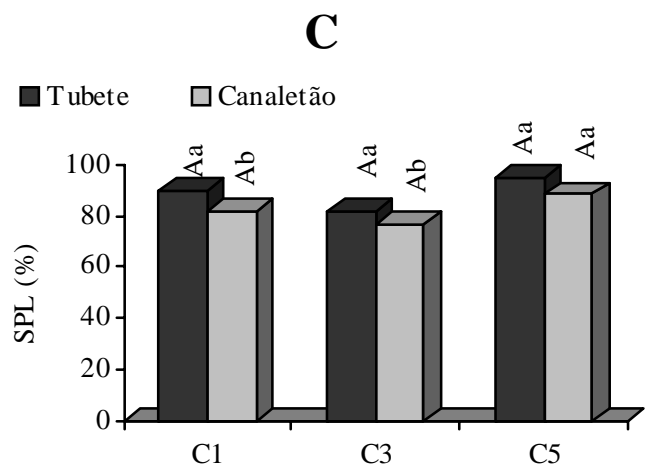

FIGURA 3: Médias de sobrevivência na saída da casa de vegetação (SOBSCV - A), na saída da casa de sombra (SOBSCS - B) e sobrevivência a pleno sol (SPS - C), para as miniestacas de Erythrina falcata. As médias seguidas de uma mesma letra maiúscula entre os tratamentos na mesma coleta e letras minúsculas entre coletas, dentro de um mesmo tratamento, não diferem entre si pelo teste de Tukey a $5 \%$ de probabilidade.

FIGURE 3: Averages of survival in the exit of the vegetation house (SOBSCV -A), in the exit of the house of shade (SOBSCS - B) and survival in full sun (EPS - C), for the minicuttings of Erythrina falcata. Means followed by the same capital letter among the treatments in the same collection and lower case among the collections, inside the same treatment, don't have differences by Tukey's Test $(\mathrm{p}<0,05)$.

É importante ressaltar que a quinta coleta de miniestacas foi realizada no período de temperaturas mais elevadas, em relação às demais, o que provavelmente proporcionou condições fisiológicas mais favoráveis ao processo de desenvolvimento e crescimento das brotações e, conseqüentemente, um resposta positiva das miniestacas ao enraizamento, o que está de acordo com Hartmann et al. (1997). 
Considerando-se os altos índices de enraizamento das miniestacas (média geral de 85,5\%), tem-se a indicação de que essa espécie apresenta boa aptidão natural ao sistema testado, ou seja, o uso de miniestacas provenientes de material seminal. Esse está de acordo com resultados obtidos por Wendling e Souza Júnior (2003) em erva-mate, no qual obtiveram média de $75 \%$ de sobrevivência das mudas. Resultados semelhantes foram obtidos por Santos et al. (2002 b), que observaram uma boa percentagem de sobrevivência da mudas, com média geral de 82,5\%, sem a aplicação de ácido indol butírico, para mogno (Swietenia macrophylla).

Segundo Hackett (1987) e Eldridge et al. (1994) uma das mais consistentes expressões da maturação em plantas lenhosas tem sido a transição da alta para a baixa capacidade de enraizamento de estacas caulinares e foliares. Para algumas espécies lenhosas, estacas de mudas juvenis, provenientes de sementes, enraízam facilmente, enquanto outras provenientes de plantas mais velhas enraízam esporadicamente, ou definitivamente não enraízam (ZOBEL e TALBERT, 1984). Em estudos realizados por Rêgo et al. (2003) os resultados obtidos com estaquia de material adulto da mesma espécie em estudo não foram satisfatórios tendo em vista que a aplicação de reguladores de crescimento, nas doses de 0; 3000; 6000 e $9000 \mathrm{mg} \mathrm{L}^{-1}$, não promoveram enraizamento das estacas.

Os resultados obtidos para altura e diâmetro do coleto, de modo geral confirmam as inferências feitas a respeito do enraizamento das miniestacas. Entre os tratamentos, a coleta 5 obteve resultados superiores para o sistema hidropônico, sendo que, nas demais coletas, não foram observadas diferenças significativas entre os sistemas de manejo adotados. Entre as coletas num mesmo sistema, não houve diferença para tubetes, já para o canaletão a coleta 5 mostrou resultados superiores para as duas variáveis analisadas (Figura 4). Cabe aqui salientar que, conforme observações feitas com a espécie, para serem plantadas no campo em local definitivo, as mudas teriam que permanecer durante, pelo menos, mais um mês no viveiro para atingir altura ideal para plantio. Nesse sentido, a produção de mudas de Erythrina falcata, via miniestaquia de material de origem seminal pode ser conseguida com boa qualidade com 4 a 5 meses de idade.

A

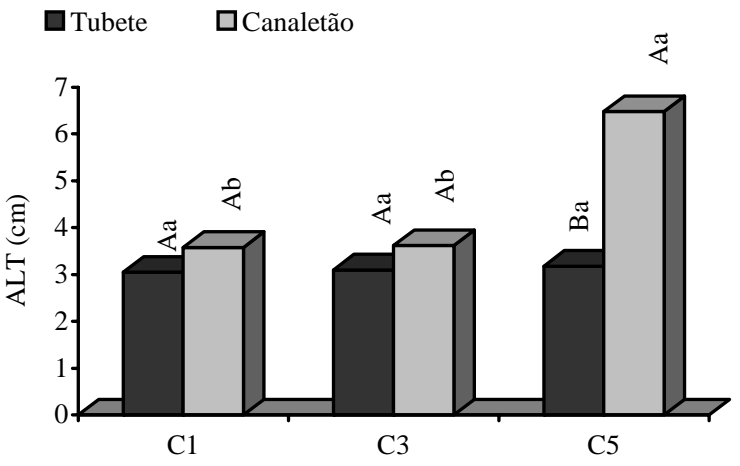

B

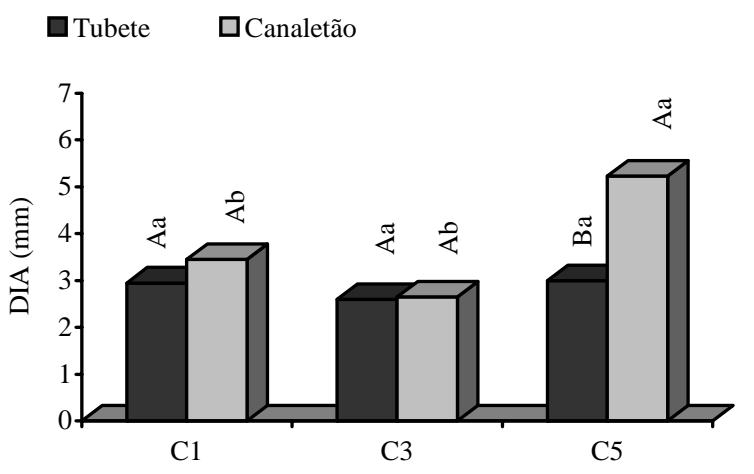

FIGURA 4: Médias de altura (ALT - A) e diâmetro do coleto (DIA - B), para as mudas de Erythrina falcata aos 70 dias após a estaquia. As médias seguidas de uma mesma letra maiúscula entre os tratamentos na mesma coleta e letras minúsculas entre coletas, dentro de um mesmo tratamento, não diferem entre si pelo teste de Tukey a $5 \%$ de probabilidade.

FIGURE 4: Averages of height (ALT - A) and collect diameter (DIA - B), of the minicuttings of Erythrina falcata70 days after rooting. Means followed by the same capital letter among the treatments in the same collection and lower case among the collections, inside the same treatment, don't have differences by Tukey's Test $(\mathrm{p}<0,05)$. 


\section{CONCLUSÃO}

Neste trabalho, conclui-se que a técnica de miniestaquia, partindo de material seminal, mostrou-se eficiente na propagação vegetativa de corticeira-do-mato (Erythrina falcata), tornando-se uma opção para a produção de plantas dessa espécie, sobretudo nas situações em que a semente é insumo limitante, ou para a propagação de espécies com sementes de baixo índice de germinação ou de difícil armazenamento. Nas condições em que foram conduzidos os estudos, podem ser conseguidas mudas aptas para o plantio definitivo com 4 a 5 meses de idade. O sistema hidropônico produziu maior quantidade de miniestacas, sendo, dessa forma, mais promissor do que o sistema em tubetes, para produzir maiores quantidades de plantas da espécie.

\section{REFERÊNCIAS BIBLIOGRÁFICAS}

CARPANEZZI, A. A.; TAVARES, F. R.; SOUSA, V. A. de. Estaquia de corticeira-do-banhado (Erythrina cristagalli L.). Colombo - PR: EMBRAPA, 2001. 6p. (Comunicado técnico, 64).

CARVALHO, P. E. R. Espécies arbóreas brasileiras. Brasília: Embrapa Informação Tecnológica, Colombo - PR: Embrapa Florestas, 2003. 1039p.

ELDRIDGE, K.; DAVIDSON, J.; HARDWIID, C.; Van WYK, G. Eucalypt domestication and breeding. Oxford: Clarendon Press, 1994. p. 228-246.

HACKETT, W. P. Donor plant maturation and adventitious root formation. In: DAVIES, T. D. ; HAISSIG, B. E.; SANKHLA, N. (eds.) Adventitious root formation in cuttings. Portland: Dioscorides Press, 1987. p. 11 - 28. (Advances in Plant Sciences Series, 2).

HARTMANN, H. T.; KESTER, D. E.; DAVIS JR., F. T. et al. Plant propagation: principles e practices. 6.ed. New York: Englewood Clipps; Prentice Hall, 1997. 770p.

HIGASHI, E. N.; SILVEIRA, R. L. V. de A.; GONÇALVES, A. N. Propagação vegetativa de Eucalyptus: princípios básicos e a sua evolução no Brasil. Circular Técnica IPEF,Piracicaba, n.192, 2000.10p.

HIGASHI, E. N.; SILVEIRA, R. L. V. de A.; GONÇALVES, A. N. Nutrição e adubação em minijardim clonal hidropônico de Eucalyptus. Circular técnica IPEF, Piracicaba, n. 194, 2002. 21p.

LORENZI, H. Árvores brasileiras: manual de identificação de plantas arbóreas nativas do Brasil. Nova Odessa : Plantarum, 1992. 352p.

MARTINEZ, H. E. P.; BARBOSA, J. G. Substratos para hidroponia. Informe agropecuário, Belo Horizonte, v.20, n.200/201, p. 81-89, 1999.

RÊGO, G. M.; ZUFFELLATO-RIBAS, K. C.; SILVA, C. A. de Enraizamento de estacas caulinares da corticeiro-doseco (Erythrina falcata (Benth) - Fabaceae). In: CONGRESSO BRASILEIRO DE SEMENTES, 13., 2003. Anais... 2003. p.65.

RUSSO, R. O. Erythrina: un genero versatil en sistemas agroflorestales del tropico humedo. Turrialba, Cosa Rica: Centro Agronomico Tropical de Investigacion y enseñanza, Catie, Programa de Recursos Naturales Renovables, 1984. $14 \mathrm{p}$.

RUSSO, R. O.; HUKE, S.; CAMACHO, Y.; ACERO, E.; BARRERA, N.; HEDGE, N.; MCCLINTOCK, E.; MUSÁLEM, M. A.; PAYNE, L.; Other uses. In: POWELL, MARK H.; WESTLEY, Sidney b. (Edts.) Erythrina Production and use: A field manual. Paia: Nitrogen Fixing Tree Association, 1993. p.26-28.

SANTOS, G. A. dos; XAVIER, A.; WENDLING, I.; OLIVEIRA, M. L. de Uso da miniestaquia na propagação clonal de Cedrela fissilis (Cedro-rosa). In: CONGRESSO E EXPOSIÇÃO INTERNACIONAL SOBRE FLORESTAS, 6., 2000, Porto Seguro. Resumos técnicos....Rio de Janeiro: Instituto Ambiental Biosfera, 2000 a. p. 203.

SANTOS, G. A.; XAVIER, A,; WENDLING, I.; OLIVEIRA, M. L. Enraizamento de miniestacas de Jequitibá rosa, Sete cascas e Mogno (Resultados Preliminares). In: SIMPÓSIO DE INICIAÇÃO CIENTÍFICA, 10., 2000, Viçosa, MG. Anais ... Viç̧osa, MG : UFV, 2000 b. p. 63.

SANTOS, G. A.; XAVIER, A.; OLIVEIRA, M. L.; WENDLING, I.; TITON, M. Miniestaquia na clonagem de Jequitibá rosa (Cariniana estrellensis). In: SIMPÓSIO DE PÓS-GRADUAÇÃO EM ENGENHARIA FLORESTAL, 1., 2001, Santa Maria, RS. Anais... Santa Maria, RS: UFSM, 2001. p. 56-66. 1 CD-ROM.

SANTOS, G. A. Propagação vegetativa de mogno, cedro rosa, jequitibá rosa e angico vermelho por miniestaquia. 2002. 75f. Monografia (Graduação em Engenharia Florestal) - Universidade Federal de Viçosa, Viçosa - MG, 2002.

SANTOS, G. A.; XAVIER, A.; PAULA, R. N.; OLIVEIRA, M. L. Miniestaquia na propagação vegetativa de mogno 
(Swietenia macrophylla King.). In: SIMPÓSIO BRASILEIRO DE PÓS-GRADUAÇÃO EM ENGENHARIA FLORESTAL, 2., 2002, Santa Maria, RS. Anais... Santa Maria, RS: UFSM, 2002. p. 394-402. 1 CD-ROM.

SILVA, A.A. da. Propagação vegetativa de essências florestais nativas. Silvicultura em São Paulo, São Paulo, v.16A, pt.2, p. 934-947. 1982.

SILVEIRA; R. L. V. de A.; HIGASHI; E. N.; SGARBI, F.; MUNIZ, M. R. A. Seja doutor do seu eucalipto. Arquivo do agrônomo, n.12, p. 29, 2001.

TITON, M. Propagação clonal de Eucalyptus grandis por miniestaquia e micropropagação. 2001. 65f. Dissertação (Mestrado em Ciência Florestal) - Universidade Federal de Viçosa, Viçosa, MG, 2001.

WENDling, I. Propagação clonal de híbridos de Eucalyptus spp. por miniestaquia. 1999. 70f. Dissertação (Mestrado em Ciência Florestal) - Universidade Federal de Viçosa, Viçosa, MG, 1999.

WENDLING, I. Rejuvenescimento de clones de Eucalyptus grandis por miniestaquia seriada e micropropagação. 2002. 98f. Tese (Doutorado em Ciência Florestal) - Universidade Federal de Viçosa, Viçosa, MG, 2002.

WENDLING, I.; SOUZA JÚNIOR, L. Propagação vegetativa de erva-mate (Ilex paraguariensis Saint Hilaire) por miniestaquia de material juvenil. In: CONGRESSO SUL-AMERICANO DA ERVA-MATE, 3.; FEIRA DO AGRONEGÓCIO DA ERVA-MATE, 2003, Chapecó. Anais... Chapecó: Epagri, 2003. 1 CD-ROM.

XAVIER, A.; WENDLING, I. Miniestaquia na clonagem de Eucalytpus. Viçosa -MG: SIF, 1998. 10p.(Informativo Técnico SIF, 11).

XAVIER, A.; SANTOS, G. A.; WENDLING, I.; OLIVEIRA, M. L. Propagação vegetativa de cedro-rosa por miniestaquia. Revista Árvore, Viçosa-MG, v. 27, n.2, p. 139-143, 2003.

ZOBEL, B.; TALBERT, J. Applied forest tree improvement. New York: North Carolina State University, 1984. $505 p$. 